\title{
Acessibilidade curricular e ensino de matemática no ensino médio integrado à educação profissional a partir da documentação pedagógica
}

\author{
Clarissa Haas ${ }^{1}$ \\ Carolina Mross Sozo ${ }^{2}$
}

\begin{abstract}
Resumo:
Aborda-se o ensino de Matemática e a acessibilidade curricular com foco no percurso escolar de um estudante com deficiência matriculado em um curso do ensino médio integrado à educação profissional do Instituto Federal de Educação, Ciência e Tecnologia do Rio Grande do Sul (IFRS) - Campus Caxias do Sul. 0 estudante selecionado estava no 1 1o ano do ensino médio integrado em 2019, sendo tratado como um caso complexo e amplamente discutido nas reuniões do Núcleo de Atendimento às Pessoas com Necessidades Educacionais Específicas (NAPNE). A metodologia qualitativa baseou-se na análise da documentação pedagógica - composta pelo Plano Educacional Individualizado (PEI) e pelas atas do NAPNE do ano de 2019. As estratégias de acessibilidade curricular em matemática registradas no PEI pelos docentes apontam a prevalência do investimento nas alternativas a partir da ação pedagógica ao invés do registro das dificuldades do estudante, evidenciando a potência do PEI como uma documentação pedagógica que escreve uma memória coletiva sobre as trajetórias escolares e corrobora a acessibilidade curricular. As atas analisadas evocam os momentos de desafios da inclusão escolar que foram refletidos coletivamente, ressaltando a importância do trabalho colaborativo entre todos os agentes envolvidos.
\end{abstract}

\section{Palavras-chave:}

Ensino de Matemática. Acessibilidade curricular. Educação inclusiva. Educação profissional. Plano Educacional Individualizado.

\footnotetext{
1 Doutora em Educação pelo Programa de Pós-Graduação em Educação da Universidade Federal do Rio Grande do Sul (PPGEdu-UFRGS). Professora efetiva da área de Pedagogia no Instituto Federal de Educação, Ciência e Tecnologia do Rio Grande do Sul - Campus Caxias do Sul. Pesquisadora integrante do Núcleo de Estudos em Políticas de Inclusão Escolar (NEPIE) da UFRGS. E-mail: cla.haas@hotmail.com. ORCID iD: https://orcid.org/0000-0002-8526-7200.

2 Acadêmica do 8o semestre da Licenciatura em Matemática IFRS - Campus Caxias do Sul. Bolsista de Pesquisa do Programa Institucional de Bolsas de Iniciação Científica pelo Conselho Nacional de Desenvolvimento Científico e Tecnológico (PIBIC) CNPq). E-mail: carolinamross@gmail.com. ORCID iD: https://orcid.org/0000-0001-6352-1004.
} 


\title{
Curricular accessibility and mathematics teaching in high school integrated to professional education as from pedagogical documentation
}

\begin{abstract}
:
This paper approaches the teaching of Mathematics and curriculum accessibility focusing on the school path of a student with disabilities enrolled in a high school course integrated to Professional Education of the Federal Institute of Education, Science and Technology of Rio Grande do Sul (IFRS) - Campus Caxias do Sul. The selected student was in the 1st year of integrated high school in 2019, being treated as a complex case and widely discussed in the meetings of the Service Center for People with Specific Educational Needs (NAPNE). The qualitative methodology was based on the analysis of pedagogical documentation - comprising the Individualized Educational Plan (PEI) and the NAPNE minutes from 2019. The strategies of curricular accessibility in mathematics registered in the PEI by the teachers point to the prevalence of investment in alternatives as from the pedagogical action, instead of the record of the student's difficulties, evidencing the power of the PEI as a pedagogical documentation that writes a collective memory about school trajectories and corroborates the curricular accessibility. The analyzed minutes evoke the moments of challenges of school inclusion that were collectively reflected, emphasizing the importance of collaborative work among all involved agents.
\end{abstract}

Keywords:

Mathematics teaching. Curricular accessibility. Inclusive education. Professional education. Individualized Educational Plan.

\section{Accesibilidad curricular y enseñanza de las matemáticas en educa- ción secundaria integrada a la educación profesional a partir de la documentación pedagógica}

\section{Resumen:}

Se aborda la educación matemática y la accesibilidad curricular enfocada en la trayectoria educativa de un estudiante con discapacidad, matriculado en un curso de Educación Secundaria integrada a la Educación Profesional del Instituto Federal de Educación, Ciencia y Tecnología de Rio Grande do Sul (IFRS) - Campus de Caxias do Sul. El estudiante seleccionado cursaba 1ํ año de secundaria integrada en 2019, siendo tratado como un caso complejo y ampliamente discutido en las reuniones del Núcleo de Atención a Personas con Necesidades Educativas Específicas (NAPNE). La metodología cualitativa se fundamentó en el análisis de la documentación pedagógica, compuesta por el Plan Educativo Individualizado (PEI) y las actas del NAPNE del año 2019. Las estrategias de accesibilidad curricular en matemáticas registradas en el PEI por los profesores señalan la importancia de invertir en alternativas basadas en acciones pedagógicas en lugar del registro de las dificultades del estudiante; destacando la fuerza del PEI como una documentación pedagógica que escribe una memoria colectiva sobre las trayectorias escolares y corrobora la accesibilidad curricular. Las actas analizadas evocan momentos de desafíos de la inclusión escolar sobre los que se reflexionó colectivamente, destacando la importancia del trabajo colaborativo entre todos los agentes involucrados.

Palabras clave:

Educación Matemática. Accesibilidad curricular. Educación inclusiva. Formación profesional. Plan Educacional Individual. 


\section{Introdução}

Esta pesquisa ${ }^{3}$ trata sobre o ensino de Matemática e a acessibilidade curricular com foco no percurso escolar de estudantes com deficiência a partir do Plano Educacional Individualizado (PEI) concebido como documentação pedagógica. Pretende-se compreender e analisar como está sendo construída a relação entre o ensino de Matemática e a acessibilidade curricular de estudantes com deficiência matriculados em cursos do ensino médio integrado à educação profissional do Instituto Federal de Educação, Ciência e Tecnologia do Rio Grande do Sul (IFRS) - Campus Caxias do Sul.

O IFRS é uma instituição federal de ensino público e gratuito. Sua criação (e dos demais institutos federais) data de 2008 (BRASIL, 2008a) e coincide com a divulgação do documento orientador da Política Nacional de Educação Especial na Perspectiva da Educação Inclusiva (BRASIL, 2008b), que marcam um momento histórico de investimento nas políticas sociais no Brasil. O IFRS tem como missão:

Ofertar educação profissional, científica e tecnológica, inclusiva, pública, gratuita e de qualidade, promovendo a formação integral de cidadãos para enfrentar e superar desigualdades sociais, econômicas, culturais e ambientais, garantindo a indissociabilidade entre ensino, pesquisa e extensão e em consonância com potencialidades e vocações territoriais. (IFRS, 2019, online).

Esta instituição possui dezessete campi, atuando na formação inicial e continuada por meio de cursos técnicos de nível médio, graduação e pós-graduação. Em 2019, contava com 27 mil alunos, 1.150 professores, 99 técnico-administrativos e duzentas opções de curso (IFRS, 2019).

Dentre os dispositivos institucionais para garantir a inclusão escolar no âmbito da instituição, cita-se o Núcleo de Atendimento às Pessoas com Necessidades Educacionais Específicas (NAPNE). De acordo com a Resolução no 020/2014 (IFRS, 2014), NAPNE é “[...] um setor propositivo e consultivo que media a educação inclusiva na Instituição" (IFRS, 2014, p. 02). Esse núcleo é formado por servidores e membros colaboradores, como discentes e familiares, estagiários e representantes da comunidade externa, sob a coordenação de um servidor efetivo. A coordenação do núcleo é feita por um coordenador/presidente, um secretário e seus respectivos suplentes (IFRS, 2014).

Considerando o campus Caxias do Sul - IFRS - como o lócus de investigação desta pesquisa, é possível afirmar que os profissionais de educação especial do referido campus são todos contratos temporários: duas tradutoras intérpretes de Língua Brasileira de Sinais (Libras), uma especialista em educação especial e uma monitora educacional. Assim, em estudos anteriores, afirma-se a necessidade de ampliar a representatividade do núcleo perante a comunidade acadêmica, considerando a previsão institucional de dispositivos que garantam seu funcionamento contínuo e regular no seu território (HAAS; SOZO, 2020).

O conceito de acessibilidade curricular é fundamental para os propósitos desta investigação. Entende-se acessibilidade curricular como um trabalho pedagógico, de dimensão individual e coletiva, que envolve estratégias pedagógicas individualizadas ou adequações razoáveis baseadas no plano de ensino comum da turma e na garantia de que todos os discentes participem do processo educativo, a partir de suas potencialidades e singularidades (HAAS; SOZO, 2020).

\footnotetext{
30 contexto de produção deste artigo trata-se do Projeto de Pesquisa intitulado Memória pedagógica sobre os processos escolares inclusivos: documentar para comunicar e incluir, coordenado pela professora Clarissa Haas e com atuação da Carolina Mross Sozo como bolsista de iniciação científica (PIBIC/CNPq). Além disso, a pesquisa resultou na elaboração do Trabalho de Conclusão de Curso (TCC) intitulado Ensino de Matemática e acessibilidade curricular no Ensino Médio integrado à Educação Profissional: percursos escolares de estudantes com deficiência, de autoria da Carolina Mross Sozo, acadêmica do curso de Licenciatura em Matemática do IFRS - Campus Caxias do Sul, com orientação da professora Clarissa Haas, no ano de 2021/1.
} 
No ano de 2019, no campus Caxias do Sul, dos 32 casos de estudantes com deficiência e/ ou necessidades educacionais específicas $(\mathrm{NEE})^{4}$ considerou-se necessária a elaboração do PEI para treze estudantes. Para este estudo, foi selecionado um estudante matriculado, em 2019, no primeiro ano do ensino médio integrado à educação profissional, tratado como um dos casos mais complexos e um dos mais discutidos nas reuniões do NAPNE do IFRS - Campus Caxias do Sul. Este estudante foi nomeado nesta pesquisa como Isaac ${ }^{5}$, tem deficiência física e está cursando o ensino médio integrado ao Técnico em Fabricação Mecânica.

\section{Caminhos investigativos}

A pesquisa desenvolvida embasa-se em uma abordagem qualitativa. De acordo com Bogdan e Biklen (1982), referendados por Lüdke e André (2017), os estudos de cunho qualitativo envolvem a obtenção de dados descritivos, o contato direto do pesquisador com a situação estudada, a ênfase ao processo ao invés do produto, a preocupação em retratar a perspectiva dos participantes.

Os caminhos metodológicos desta pesquisa foram construídos a partir das concepções sobre documentação pedagógica (MARQUES; ALMEIDA, 2012; 2017; MALAGUZZI, 2016; FOCHI, 2018; PINAZZA; FOCHI, 2018; HAAS; SOZO; RODRIGUES, 2020; TEZZARI, 2020). Do ponto de vista dos estudos do campo das metodologias de pesquisa, podemos incluir a documentação pedagógica como uma dimensão da pesquisa documental, a qual tem por característica “[...] tomar como fonte de coleta de dados apenas documentos, escritos ou não, que constituem o que se denomina de fontes primárias" (MARCONI; LAKATOS, 2019, p. 189).

Portanto, este estudo documental foi baseado na escrita do PEI do discente comparado ao plano de ensino do componente curricular de Matemática do primeiro ano do ensino médio integrado à educação profissional do IFRS e também nas atas de reunião do NAPNE - Campus Caxias do Sul.

\section{A documentação pedagógica}

A partir da história da educação, é possível identificar diferentes estudiosos, desde o início do século XX, que abordam o papel do registro pedagógico. Citam-se: Loris Malagguzzi (19201944), pedagogo italiano, considerado o precursor da abordagem de Reggio Emília; Celestin Freinet (1896-1966), pedagogo francês que se dedicou à educação das crianças pequenas; Janusz Korczak (1878-1942), pseudônimo para Henryk Goldszmit, polônes, descendente de judeu - dentre as diversas ocupações que desempenhou, destaca-se sua atuação como pedagogo e diretor de uma casa para crianças e adolescentes em situação de abandono. Ainda no contexto brasileiro, aponta-se, nos anos 80, o trabalho de Madalena Freire acerca da centralidade do registro como instrumento metodológico do professor, juntamente com a observação, com o planejamento e com a avaliação (MARQUES; ALMEIDA, 2017).

Loris Malaguzzi (2016) afirma caber aos docentes descobrir modos de documentar e comunicar as experiências das crianças na escola, por meio da organização qualitativa de um fluxo constante de conhecimentos. Para o autor, essa documentação comunica e mobiliza os diferentes atores do

\footnotetext{
4 O IFRS adota a nomenclatura “Necessidades Educacionais Específicas (NEE)” conceituando-a como todas aquelas pessoas cujas necessidades educacionais são provenientes de deficiências, de altas habilidades/superdotação, transtornos globais de desenvolvimento e outros transtornos de aprendizagem (IFRS, 2014).

5 No âmbito da pesquisa, foi analisada a trajetória de dois estudantes e as análises da documentação pedagógica foram complementadas com entrevistas realizadas com os professores de Matemática desses alunos. No entanto, no presente artigo, abordamos apenas o caso de um dos alunos. Para manter sigilo quanto à identidade do discente, ele será nomeado com o nome de um cientista que tem articulação com a área de Educação Profissional que o estudante cursa, sendo ele: Isaac (Newton).
} 
processo educativo: as crianças, tornando-as ainda mais curiosas, interessadas e confiantes; as famílias, no reconhecimento e na apreciação do desenvolvimento de seus filhos; os professores, no questionamento constante sobre o seu ensino.

Célestin Freinet, a partir de diversos instrumentos e estratégias participadas pelas crianças, propôs uma "[...] documentação de experiências e saberes que se integram ao trabalho pedagógico cotidiano" (MARQUES; ALMEIDA, 2017, p. 227). Assim como Freinet, Jannusz Korczak registrava anotações das suas observações de seus estudantes e embasava sua prática por meio de uma multiplicidade de estratégias, nas quais valorizava a autonomia da criança. Ele entendia que a confiança e o respeito às crianças era muito importante para o desenvolvimento do seu projeto educativo e tinha a autogestão como um de seus princípios pedagógicos (KORCZAK, 1997).

Marques e Almeida (2012, p. 445, grifo do autor) conceituam documentação pedagógica como "[...] sistematização do trabalho pedagógico, produção de memória sobre uma experiência, ação que implica a seleção e a organização de diferentes registros coletados durante o processo". Essas autoras afirmam que é necessário selecionar o foco desta documentação, coletar e elaborar materiais; isso "[...] perpassa a narração e permite o aprofundamento da compreensão da experiência e a comunicação de uma mensagem" (MARQUES; ALMEIDA, 2012, p. 453).

A documentação pedagógica não deve ser confundida com um simples registro das práticas pedagógicas realizadas com os estudantes. Essa abordagem depende de "[...] uma alta qualidade de registros de observação e de grande competência na coleta, na produção e na organização dos dados" (PINAZZA; FOCHI, 2018, p. 23). Quando utilizada de forma correta, “[...] a estratégia da documentação pedagógica se converte em uma ferramenta poderosa na reconstrução de significados" (PINAZZA; FOCHI, 2018, p. 24). Para Haas, Sozo e Rodrigues (2020, p. 09), a potência da documentação pedagógica está no "[...] entendimento do caráter processual do registro [...]", a qual deve ser atualizada constantemente, e "[...] cuja memória do vivido pode antecipar estratégias para o período/ano escolar seguinte".

Fochi (2018), a partir da perspectiva malaguzziana, considera que a escuta é um dos pilares centrais da documentação pedagógica, a qual tem a função de "[...] tornar visíveis as imagens da criança, do professor e da escola, para problematizar e atualizar nossas concepções e práticas" (FOCHI, 2018, p. 155). O autor menciona que o professor deve compreender, refletir e interpretar as atuações do estudante para que possa planejar a continuidade do seu fazer docente, pois essas reflexões do cotidiano são uma "[...] oportunidade de tomada de consciência sobre a ação docente" (FOCHI, 2018, p. 151). Ainda cita como pilares da documentação pedagógica: a observação, o registro como forma de percepção da ação docente e dos estudantes nos cotidianos escolares; a interpretação dos registros para projetar, planejar e produzir conhecimento com os estudantes (FOCHI, 2018). Embora a pesquisa de Fochi (2018) dirija-se às infâncias, entende-se que os pilares da documentação pedagógica descritos por ele são pertinentes em todos os níveis e etapas de ensino.

Sendo assim, enfatiza-se a importância da documentação pedagógica como atividade docente reflexiva envolvendo momentos distintos e complementares da ação educativa, e defendem-se as características do registro como formativas. Especificamente no caso dos estudantes com deficiência e/ou NEE, salienta-se o caráter do registro como memória da trajetória, bem como o viés político e pedagógico envolvendo a visibilidade dos investimentos na promoção e qualificação das estratégias de acessibilidade curricular.

\section{Plano Educacional Individualizado (PEI) e implicações para a acessibilidade curricular}

Em dezembro de 2018, entrou em vigor a Instrução Normativa no 12 (IFRS, 2018), que visava a contribuir na organização dos processos de ensino dos estudantes com necessidades educacionais 
específicas. Essa normativa regulamentava os fluxos e procedimentos de identificação, acompanhamento e realização do Plano Educacional Individualizado (PEI) dos estudantes com necessidades educacionais específicas do IFRS. Conforme essa norma, deve-se elaborar um PEI para cada um desses estudantes que necessitem de "adaptações curriculares".

Em setembro de 2020, houve uma atualização da Instrução Normativa que trata a respeito do PEI. Dessa forma, a Instrução Normativa no 12/2018 (IFRS, 2018) foi revogada, sendo substituída pela Instrução Normativa no 07/2020 (IFRS, 2020). Basicamente, a atualização se deu pela alteração do termo "adaptação curricular" por "acessibilidade curricular" e a inclusão do termo "adaptações razoáveis".

Além da alteração/substituição do termo "adaptação curricular", outra mudança é com relação à definição do PEI. Na antiga normativa, o PEI era considerado como sendo "um registro das adaptações individualizadas", entre outros tópicos. Agora, de acordo com o $\S 2^{\circ}$ do art. $1^{\circ}$ da normativa atual, o PEI é

[...] um recurso pedagógico com foco individualizado no estudante e tem por finalidade otimizar o processo de ensino e aprendizagem de pessoas com deficiência ou outras especificidades. É um plano e registro das estratégias que visam promover acessibilidade curricular e que são necessárias para o estudante alcançar as expectativas de aprendizagem definidas para ele. [...] É uma proposta pedagógica compartilhada, que deve ser construída de forma colaborativa pelos profissionais da instituição de ensino, pais e/ou responsáveis e, quando possível, pelo próprio estudante. (IFRS, 2020, p. 01).

O art. $3^{\circ}$ (IFRS, 2020, p. 03) cita três formas de identificação dos estudantes com NEE: na matrícula, de forma espontânea e por identificação de docentes e/ou técnico- administrativos ligados ao setor de ensino. Todavia, de acordo com o $\S 1^{\circ}$ do art. $4^{\circ}$ (IFRS, 2020), é garantido o direito de o estudante ou seu responsável legal recusar a implementação dos apoios na forma do PEI.

Conforme os artigos $6^{\circ}$ e 7 (IFRS, 2020), o Setor Pedagógico, a Assistência Estudantil e o NAPNE são os responsáveis por coletar e registrar as informações sobre esses estudantes, e o PEI deve ser construído de forma colaborativa entre essas partes e o corpo docente. Ainda, no parágrafo único do art. $7^{\circ}$, é citado que deve ser previsto horário de atendimento individualizado pelos docentes para estes alunos. Está previsto no art. $8^{\circ}$ (IFRS, 2020) que deverão ser organizados encontros periódicos com os docentes dos alunos com necessidades educacionais específicas "[...] a fim de discutirem as especificidades deles e buscarem, em conjunto, estratégias de ensino para aprendizagem, além de acessibilidades curriculares que se façam necessárias” (IFRS, 2020, p. 04).

De acordo com Sonza, Vilaronga e Mendes (2020), em pesquisa que aborda o PEI no âmbito de dois institutos federais, o ato de documentar as ações desenvolvidas para os estudantes com deficiência auxilia a instituição a pensar em estratégias para esses alunos. Ainda, afirmam que "O PEI é mais do que o preenchimento do próprio formulário, mas todo processo de pensar nas medidas possíveis para garantir o direito do aluno de ter acesso ao conhecimento" (SONZA; VILARONGA; MENDES, 2020, p. 15).

Ainda, com base nos estudos de Ianes (2014) sobre a escola italiana, na qual há a prática consolidada da utilização do PEI para acompanhamento dos estudantes com deficiência e para planejamento de estratégias colaborativas entre professores do ensino comum e especializado, afirma-se o PEI como "um indispensável documento de programação da ação educativa e didática" (IANES, 2014, p. 11). O referido autor aborda a importância do investimento coletivo na elaboração de uma ampla gama de possibilidades e competências educativas aos estudantes com deficiência, a partir do PEI, tratando-o como um "projeto de vida".

Reconhece-se que, por se tratar de uma instrução recente no IFRS, a elaboração do PEI está em processo de familiarização e apropriação por parte dos docentes. Assim, o ano de 2019 pode

6 Tradução livre do original em italiano. 
ser tratado como um período de aprendizagem institucional no que concerne à implementação do PEI. Entende-se que, a partir desse documento, novos professores conseguem ter acesso ao que já foi trabalhado com um estudante, garantindo a continuidade das estratégias bem-sucedidas ao longo de sua trajetória acadêmica. Também é uma forma de comunicar aos estudantes e/ou seus responsáveis os caminhos de planejamento e implementação da acessibilidade ao currículo.

\section{Elementos textuais do PEI}

Detalham-se, a seguir, os elementos textuais para elaboração do PEI, de acordo com a Instrução Normativa n 07/2020 (IFRS, 2020). Primeiramente, há os tópicos de identificação contemplando um breve histórico do estudante sobre sua trajetória escolar. Há um campo específico para detalhar as necessidades educacionais específicas, a fim de que o professor possa elaborar estratégias de acordo com as especificidades do estudante. Os próximos campos tratam dos conhecimentos, das habilidades, capacidades e dos interesses do discente, bem como das suas dificuldades em cada área do conhecimento. No que diz respeito às adaptações razoáveis e/ ou acessibilidade curricular, o documento cita a formulação dos objetivos específicos, a partir do plano geral do componente curricular e dos conteúdos programáticos, sendo possível priorizar e/ ou substituir conteúdos. Ainda, há indicação para registro da metodologia utilizada e da forma de avaliação, em conformidade com o desempenho do estudante. O instrumento também aponta a necessidade de elaboração de um parecer descritivo sobre os avanços do estudante e as propostas que tiveram, ou não, êxito. Ademais, há o apontamento de que o PEI deve ser atualizado a cada novo período (semestre/trimestre).

Quanto à menção no documento sobre a possibilidade de "priorizar ou substituir" conteúdos, enfatiza-se a necessidade de cautela na tomada das decisões pedagógicas. "A definição do plano de acessibilidade curricular não pode preceder o encontro com o estudante e as incertezas do processo pedagógico devem ser valoradas como elementos para avançar qualitativamente na aposta da educabilidade do outro" (HAAS; SOZO, 2020, p. 66).

\section{PEI do Isaac}

Abordam-se, a seguir, as categorias iniciais do $\mathrm{PEI}^{7}$ de Isaac, que trazem dados sobre a trajetória do estudante com foco no seu percurso escolar e que são responsabilidade de elaboração coletiva do Departamento de Ensino, Setor de Assistência Estudantil e NAPNE.

Em decorrência da paralisia cerebral, Isaac teve as funções motoras e a fala comprometidas, mas não houve comprometimento na parte intelectual. Utiliza cadeira de rodas motorizada para se locomover, e são poucos os objetos que consegue segurar. Sua fala é de difícil compreensão; ele tenta se comunicar de diferentes maneiras até que entendam o que ele está falando. Consta no PEI que seu modo de aprendizado é auditivo e visual e que se desconcentra com facilidade. Ele é muito sociável e comunicativo e aparentemente acolhe bem sua condição de deficiência.

No que se refere à sua escolarização anterior, lê-se no PEI de Isaac que seu ensino fundamental foi pouco aproveitado do ponto de vista da aquisição de conhecimentos, pois "[...] não era exigido todo o seu potencial”. Logo, possui uma defasagem no que diz respeito aos conteúdos do ensino fundamental. Na antiga escola, o aluno participava do Atendimento Educacional Especializado (AEE), que acontecia na sala de aula e na sala de recursos do AEE, para exploração de outras estratégias. Sua assiduidade às aulas é afirmada como um aspecto positivo em sua trajetória escolar.

$7 \mathrm{O}$ acesso às informações do PEI do aluno foi autorizado pela Coordenação do NAPNE para fins desta pesquisa. 
Acerca das habilidades linguísticas, o PEI traz as informações de que o aluno faz leitura silabada, com muitas pausas; têm mais facilidade de leitura e compreensão dos escritos feitos com letra bastão (ou de imprensa) e de textos estruturados em parágrafos curtos. Em parte, a leitura vagarosa do aluno se dá em função de suas questões fonológicas. Logo, aulas com vídeos devem ter pausas para discussão, para um melhor acompanhamento. Não consegue escrever da forma convencional, ou seja, utilizando lápis, caneta e caderno. Suas avaliações devem ser estruturadas com sequenciamento de imagens e frases curtas, sempre que possível. Ele utiliza materiais didáticos manipuláveis para estabelecer relações e conceitos matemáticos. Necessita de monitor/a educacional para o apoiar no deslocamento pelas dependências da escola, alimentação e higiene.

Isaac possui uma rotina intensa no contraturno, envolvendo atendimentos da área da saúde e atividades físicas. Faz sessões de fisioterapia, fonoaudiologia, terapia ocupacional e participa de atividades esportivas, tais como bocha paralímpica, futebol, xadrez, entre outras. Dessa forma, tem poucos horários disponíveis para realizar as atividades de aprendizagem propostas pelos professores em casa.

O aluno ingressou no IFRS - Campus Caxias do Sul - no ano de 2018 no primeiro ano do ensino médio técnico. Constam no PEI as dificuldades enfrentadas em seu primeiro ano na instituição e o modo como a equipe buscou suprir algumas dessas dificuldades no ano seguinte.

Ele possui um histórico de repetência no primeiro ano do ensino médio. Em 2018, não houve muitas adequações para o aluno, e ele possuía uma monitora educacional ${ }^{8}$ que realizava a maior parte das tarefas por ele (SILVA et al., 2019; HAAS; MORO, 2020). Durante o ano de 2019 o aluno contou com o apoio da Tutoria Acadêmica, na forma de monitoria de informática acessível, realizada por dois estudantes da graduação da instituição, bolsistas de pesquisa e membros do NAPNE, para exercitar o uso das ferramentas tecnologias digitais de acessibilidade. O objetivo da tutoria era "oportunizar ao estudante maior autonomia, de modo que ele mesmo possa realizar os registros e desenvolver os conteúdos com apoio de recursos adequados" (SILVA et al., 2019, p. 41). Conforme Silva et al. (2019), a tutoria ocorria uma vez por semana, com uma hora de duração e as atividades eram desenvolvidas de acordo com temas de interesse do próprio aluno. Todas as atividades eram realizadas no notebook, com a utilização do teclado virtual do Windows, mouse adaptado (joystick) e prancha do alfabeto (utilizada como alternativa à fala mediante à soletração de palavras ou frases curtas). Salienta-se que os recursos de Tecnologia Assistiva (TA) para este aluno foram desenvolvidos pelo Centro Tecnológico de Acessibilidade (CTA) do IFRS.

Com o apoio dessa tutoria e dos docentes, o estudante começou a utilizar o computador regularmente em sala de aula, e todas as formas de registros de conteúdos passaram a ser feitas de forma digital em seu notebook. Assim, foi criado um caderno digital ${ }^{9}$ para cada disciplina e, no final de cada trimestre, o material foi impresso e encadernado, para que o aluno pudesse dispor de suas produções na forma física.

Consta também no PEI de Isaac a orientação de que as atividades de aprendizagem levem em consideração o tempo de que ele precisa, equilibrando quantidade e qualidade.

$\mathrm{Na}$ sequência, abordam-se as categorias do PEI que foram preenchidas pelos professores ${ }^{10}$ de Isaac, referentes ao plano de acessibilidade curricular.

No ano de 2019, Isaac estava matriculado em doze disciplinas: Artes, Desenho Técnico, Educação Física I, Filosofia I, Física I, Gestão da Qualidade, Informática Instrumental, Introdução

\footnotetext{
8 Destaca-se que a atribuição da monitora é exclusiva para os cuidados de higiene, locomoção e alimentação de Isaac.

9 O Departamento de Ensino e o NAPNE criaram uma pasta no Google Drive intitulada Cadernos digitais, com o intuito de que o estudante tivesse documentos online das aulas de cada disciplina para seu estudo e registro.

10 No ano de 2019, o estudante Isaac teve dois professores de Matemática. Para manter sigilo quanto à identidade dos docentes, ao se referir a eles, serão utilizados nomes de matemáticos renomados na área, sendo eles: Pitágoras (de Samos) e Euclides (de Alexandria). Ambos os professores foram contratados como substitutos, sendo que Pitágoras ingressou no início do ano letivo e Euclides assumiu a turma no mês de agosto.
} 
à Fabricação Mecânica, Língua Portuguesa e Literatura Brasileira I, Matemática I, Química I e Sociologia I. Dessas, apenas uma disciplina não teve nenhum registro no PEI, e duas possuíam registros incompletos.

Como estratégias de acessibilidade curricular, foram mencionados: uso de mouse adaptado (joystick), computador e teclado virtual; materiais disponibilizados em pasta do Google Drive intitulada Cadernos digitais; entrega de materiais impressos; uso de imagens, esquemas explicativos, resumos e vídeos demonstrativos; evitação de textos longos; auxílio da monitora; questões curtas e objetivas; trabalhos práticos com o uso do computador.

Pode-se afirmar que, em quatro disciplinas, seguiram-se os mesmos conteúdos propostos no plano de ensino comum da turma, observando as especificidades do estudante. Nas demais disciplinas, Isaac teve acesso aos mesmos conteúdos, focando em conceitos gerais, sem o mesmo aprofundamento que os demais colegas.

No que tange às metodologias utilizadas, citam-se: protótipos ou modelos físicos; materiais ilustrativos; questões de associações; atendimentos individualizados no contraturno; questionamentos, conversas e explicações direcionadas ao aluno; demonstrações práticas; recursos de Tecnologia Assistiva; leitura e interpretação de imagens; uso do software GeoGebra ${ }^{11}$ para esboço de gráficos; uso do editor de texto Word para introduzir a escrita de expressões matemáticas; slides e figuras ilustrativas; simulações de computador; uso de vídeos; exercícios e trabalhos práticos adaptados no computador; e situações do cotidiano do estudante.

Em relação às avaliações para Isaac, foram mencionadas propostas diversificadas, tais como: valorização dos aspectos qualitativos; auxílio durante a avaliação no processo de desenvolvimento da compreensão; participação nas aulas; progresso do estudante; provas e trabalhos em duplas ou pequenos grupos; adaptação de exercícios com enunciados mais simples e apoio complementar com figuras; prova igual à dos demais colegas, com o uso do computador e adaptação no tempo de resolução; prova com ênfase nos conhecimentos práticos-instrumentais; possibilidade de uso de imagens e vídeos; exercícios de verdadeiro ou falso, nos quais a frase era lida para o estudante, que indicava a resposta na prancha do alfabeto; utilização dos softwares GeoGebra e Word.

Quanto ao componente curricular de Matemática, o professor Pitágoras fazia associações de conceitos matemáticos ao cotidiano do estudante, como a venda de doces realizada pelo estudante e o conteúdo de Funções, e utilizava canais didáticos do YouTube na explanação dos conteúdos. O professor Euclides, por sua vez, destaca que utilizava o software GeoGebra regularmente, visto que o Isaac possuía facilidade em trabalhar com recursos tecnológicos. Como desafio principal, o professor Pitágoras citou a dificuldade de o estudante em aplicar os conceitos matemáticos em situações diferentes daquelas utilizadas na explicação inicial do conteúdo. Euclides tece elogios à assiduidade, atenção e curiosidade do estudante e menciona as suas dificuldades na comunicação com ele. Destaca que o estudante tinha iniciativa em interagir com o professor, mas que ele nem sempre o compreendia, tendo que recorrer ao apoio da monitora.

Durante o ano letivo de 2019, os objetivos propostos ao Isaac foram: representar um ponto no plano cartesiano; identificar os quadrantes do plano cartesiano; conhecer o conceito de função, função afim e função quadrática; estimular a produção de expressões matemáticas e enfatizar a relação com as funções; aprimorar a escrita de notação matemática para desenvolver as habilidades dependentes da escrita; realizar a visualização e a construção gráfica de funções no GeoGebra. A cronologia da escrita dos objetivos no PEI mostra que eles foram construídos e ajustados ao longo do ano escolar em atenção ao feedback do estudante nas atividades propostas.

11 GeoGebra é um software de matemática dinâmica gratuito para todos os níveis de ensino, que combina geometria, álgebra, tabelas, gráficos, estatística e cálculo numa única aplicação. O aplicativo, disponível em múltiplas plataformas, traz diversos recursos interativos e dinâmicos para a sala de aula, tornando-o uma ferramenta acessível e de grande valia para o processo de ensino e aprendizagem, podendo ser utilizado por estudantes com ou sem deficiência (CANAL DO ENSINO, [201-]). Esse software pode ser utilizado de forma online ou através do aplicativo, o qual está disponível para download em: https://www.geogebra.org/download. 
As avaliações foram realizadas com o auxílio do computador e elaboradas com caráter individualizado para o estudante, contemplando somente a identificação e a diferenciação entre as funções trabalhadas e produção de expressões no Word, a partir dos esboços produzidos no GeoGebra. Os exercícios do plano cartesiano eram realizados no GeoGebra, e os outros eram respondidos diretamente no arquivo digital. A estratégia do professor Euclides envolvia estruturar um modelo de escolha visual dupla para construção de exercícios idênticos aos da turma no GeoGebra e de pequenas tarefas de escrita no Word.

No parecer do aluno, o professor Pitágoras relata que o Isaac entende as relações entre as variáveis, mas tem dificuldades quanto aos conceitos matemáticos. Ele consegue fazer operações básicas; contudo, quando se trata de números decimais, necessita do uso da calculadora. Também possui dificuldade com operações que envolvem mais de dois algarismos e não consegue distinguir números positivos e negativos imediatamente. O professor Euclides explica que quase todas as solicitações feitas ao aluno foram elaboradas utilizando recursos visuais. Durante as aulas e nos momentos de avaliação pontual, o professor concluiu que o estudante era capaz de identificar e distinguir uma função quadrática e uma linear, uma linear e uma modular, mas não conseguiu diferenciar duas funções modulares com coeficientes distintos. Ainda reforça que a dificuldade do aluno deve ser contornada com a maior utilização do computador e deixa como sugestão que, no próximo ano letivo, sejam exploradas as habilidades do estudante com planilhas eletrônicas, tais como o software Excel.

Os registros dos professores demonstram que o estudante assimilou noções gerais do conteúdo proposto como currículo de matemática no primeiro ano do ensino médio e apontam alternativas para a continuidade da ação pedagógica com o discente.

\section{Análise das atas de reunião do NAPNE}

No ano de 2019, foram realizadas vinte reuniões registradas pelo NAPNE, das quais dez mencionaram o aluno Isaac, sendo cinco atas extraordinárias e cinco ordinárias. Analisamos as atas à luz da concepção de Tezzari (2020), tentando resgatar as experiências, a "análise do vivido", não tratando-as apenas como formalidades.

Os assuntos abordados explicitam a articulação entre a família e a escola e entre os diferentes agentes da escola responsáveis pela inclusão escolar. São assuntos mais abordados: as dificuldades econômicas da família do estudante, repercutindo na falta de acesso à internet e computador em casa, para realização das tarefas escolares, e os encaminhamentos exitosos feitos pela instituição para obter a doação de um notebook ao estudante; as atribuições da monitora educacional do discente e o apoio da técnica de educação especial; a acessibilidade arquitetônica, como apoios necessários no uso do banheiro; a acessibilidade curricular do estudante, por meio das oficinas de informática acessível e o atendimento individualizado, ambos no contraturno às aulas.

Com relação à articulação com a família, pode-se mencionar a preocupação da mãe de Isaac com a acessibilidade curricular do filho, decorrente de um diálogo com profissionais da área da saúde que atendem o estudante. Conforme narrativa da mãe, a terapeuta ocupacional do estudante questionou a disponibilização de materiais em formato acessível às necessidades e possibilidades do estudante, por parte dos professores. Percebe-se a importância do assunto atribuído pela família quando a fala é proveniente de um profissional da saúde, confirmando a tradição histórica da prevalência do discurso médico-psicológico em detrimento do pedagógico (CHRISTOFARI; FREITAS; BAPTISTA, 2015; OLIVEIRA; CAIADO, 2020).

Acerca do papel desempenhado pela monitora educacional, há registro nas atas de que informava antecipadamente à mãe de Isaac quando não iria comparecer à instituição, para que não levasse o aluno às aulas neste dia - situação equivocada, de que a equipe diretiva e o NAPNE não tinham conhecimento. $O$ caso com a monitora indica como é complexo construir uma relação 
pedagógica envolvendo mais profissionais, de modo que todos aprendam a trabalhar juntos a partir das atribuições de seus cargos. Fica evidente que a monitora assumiu para si funções que não eram as suas.

Consta nas atas a narrativa das dificuldades da monitora educacional com Isaac, devido ao seu comportamento do estudante de negação e resistência à presença permanente da monitora junto dele, o que é justificável, dado seu tempo de vida juvenil. Essa demanda reforçou a importância da Tecnologia Assistiva na escolarização do discente, como campo de conhecimento capaz de lhe garantir certa autonomia.

As atas também narram o investimento nas oficinas de informática acessível no turno inverso à escolarização, para que o estudante pudesse utilizar os recursos de tecnologia de que já dispõe em sala de aula com mais eficiência, sem necessidade de se apoiar constantemente na monitora. No relato, percebe-se o direcionamento da gestão do NAPNE para o uso da Tecnologia Assistiva (TA) como recurso de mediação e potencialização da aprendizagem do estudante. Segundo Oliveira, Simon e Brenner (2014), os recursos de TA

[...] visam articular programas capazes de promover a inclusão sócio-digital de pessoas com necessidades educacionais especiais, buscando sempre o respeito às diferenças e a igualdade de oportunidades. (OLIVEIRA; SIMON; BRENNER, 2014, p. 194).

Em junho de 2019, houve o ingresso da técnica em educação especial no campus Caxias do Sul, que passou a acompanhar Isaac em sala de aula em alguns momentos pontuais, a fim de diagnosticar suas potencialidades e dificuldades e melhor orientar os professores na formulação das estratégias de acessibilidade curricular. As atas trazem apontamentos delimitados sobre as narrativas dessas observações e desses apoios realizados pela técnica. Cabe frisar que o IFRS não possui o Atendimento Educacional Especializado institucionalizado como dispositivo pedagógico. A contratação dessa profissional ocorreu mediante ação pública iniciada junto ao Ministério Público pela família de Isaac.

As últimas atas do ano letivo de 2019 apontam elogios à evolução do Isaac, ele por estar utilizando seu computador regularmente em sala de aula, o que contribui para a sua aprendizagem e motivação nos estudos. Afirmam a importância dos atendimentos individualizados no contraturno pelos docentes a Isaac e, de modo geral, aos estudantes com necessidades educacionais específicas da instituição.

\section{Considerações finais}

Defende-se o PEI como documentação pedagógica, salientando-se a importância de se considerar que esse documento é uma memória, o qual vai ser lido ao longo do tempo por outros professores, justificando a necessidade de uma escrita generosa em detalhes e clara em sua formulação. Assim, reitera-se "[...] o caráter de potência do PEI como documentação pedagógica da trajetória de escolarização dos estudantes com deficiência e/ou NEE, tendo em vista o caminho da acessibilidade curricular como meta da inclusão plena" (HAAS; SOZO; RODRIGUES, 2020, p. 13).

O legado histórico de diferentes educadores e estudiosos acerca da documentação pedagógica permite a compreensão de que a estratégia não é algo recente na história da educação, embora continue sendo um desafio a sua tradução nas práticas ${ }^{12}$. Ainda que a documentação analisada

12 Embora as entrevistas realizadas com os professores de matemática, autores da documentação pedagógica do PEI em análise, não tenham sido foco deste estudo, considera-se importante registrar que o diálogo com os professores revelou que nem todas as estratégias elaboradas por eles foram registradas no $\mathrm{PEI}$, por diferentes motivos, evidenciando a necessidade da qualificação deste instrumento. 
aponte a necessidade de que os profissionais da instituição evoluam nas formas de proceder o registro pedagógico, fica evidente que os professores reforçam as estratégias bem-sucedidas mais do que as dificuldades do aluno, de modo que o documento cumpre com o propósito de fomentar as alternativas para acessibilidade curricular dos estudantes com deficiência.

Das estratégias registradas no PEI no componente curricular de Matemática, citam-se: a utilização de recursos visuais; ferramentas de Tecnologia Assistiva, como o notebook com teclado virtual, o mouse adaptado (Joystick) e a prancha do alfabeto; outras ferramentas digitais, tais como o software GeoGebra, canais didáticos do YouTube e o editor de texto Word; a transposição de conceitos matemáticos abstratos para o cotidiano dos estudantes. Também se proveu acessibilidade para o estudante, com o apoio da monitora educacional e da técnica em educação especial, com os atendimentos individualizados por parte dos docentes e com a tutoria acadêmica na forma oficinas de informática acessível, sendo que ambas ocorriam no contraturno.

Observa-se que os conteúdos matemáticos abordados no PEI do estudante estão de acordo com o plano de estudos de sua turma de referência. Os objetivos de aprendizagem são ajustados conforme o feedback do estudante e as estratégias pedagógicas contemplam suas singularidades.

No que se refere à análise das atas do NAPNE, frisa-se que os desafios da inclusão escolar podem ser superados com o trabalho colaborativo e muito diálogo entre todos os agentes envolvidos.

É possível constatar que, no caso do estudante em investigação, tanto no PEI como nas atas do NAPNE, há um incentivo e uma aposta no uso da tecnologia assistiva e de outras alternativas envolvendo ferramentas digitais, pela possibilidade contundente de ampliação de sua autonomia e pelo apelo positivo desses recursos junto às culturas juvenis.

Considera-se um movimento significativo a mudança da nomenclatura - de adaptações curriculares à acessibilidade curricular - utilizada no documento do IFRS que institucionaliza o PEI. Neste viés, Mesquita (2010, p. 313) deixa claro que "[...] o ponto de partida da inclusão deve ser um currículo acessível a todos os estudantes". Haas e Baptista (2015, p. 14), ao defenderem a acessibilidade curricular, mencionam que

[...] parece um caminho promissor [...] aquele que problematiza o equilíbrio entre as dimensões coletiva e individual que devem estar presentes na escolarização de um estudante com deficiência, de modo que sua trajetória seja individualizada, mas ao mesmo tempo possa ser reconhecida como parte da história coletiva construída na sala de aula com seus pares. (HAAS; BAPTISTA, 2015, p. 14).

Xavier (2018), em pesquisa documental, aponta como sentidos atribuídos ao termo acessibilidade curricular "[...] a manutenção de um currículo comum para todos, que pode se tornar acessível por meio de práticas pedagógicas e, consequentemente, se aproximam da perspectiva das adaptações razoáveis dispostas na Lei Brasileira de Inclusão (LBI)” (XAVIER, 2018, p. 53).

Sem desconsiderar a herança clínica do PEI como estratégia pedagógica vinculada aos espaços escolares substitutivos (escolas e classes especiais), busca-se ressignificar o uso do dispositivo. A ênfase à adjetivação do plano educacional como "individualizado" é dada pela via do registro pedagógico individualizado da trajetória do estudante, buscando distanciar-se da concepção de individualização do currículo. Ao contrário, prima-se para que o estudante se sinta parte do coletivo escolar, compartilhando dos conhecimentos disponíveis a todos.

Desse modo, reafirma-se o acesso ao currículo como premissa do trabalho pedagógico e o PEI como uma ferramenta ampla com o intuito de prover a acessibilidade curricular do estudante com deficiência e/ou NEE. São premissas para esse intento: a articulação de um planejamento docente que contemple o perfil individualizado do estudante e a proposta pedagógica de sua turma de referência; a documentação pedagógica cuidadosa e regular das estratégias e a ação colaborativa entre os profissionais da educação envolvidos na inclusão escolar do estudante. 


\section{Referências}

BRASIL. Lei $n^{\circ}$ 11.892, de 29 de dezembro de 2008. Institui a Rede Federal de Educação Profissional, Científica e Tecnológica, cria os Institutos Federais de Educação, Ciência e Tecnologia, e dá outras providências. Brasília, DF: Presidência da República, 2008a. Disponível em: http://www.planalto.gov.br/cciviL_03/_Ato2007-2010/2008/Lei/ L11892.htm. Acesso em: 17 ago. 2020.

BRASIL. Política Nacional de Educação Especial na Perspectiva da Educação Inclusiva. Brasília, DF: Ministério de Educação e Cultura (MEC), 2008b. Disponível em: http://portal.mec.gov.br/arquivos/pdf/politicaeducespecial.pdf. Acesso em: 16 mar. 2020.

CANAL DO ENSINO. Conheça e entenda os conceitos do GeoGebra. [201-]. Disponível em: https://canaldoensino.com. br/blog/conheca-e-entenda-os-conceitos-da-geogebra. Acesso em: 25 jan. 2021.

CHRISTOFARI, Ana Carolina; FREITAS, Claudia Rodrigues de; BAPTISTA, Claudio Roberto. Medicalização dos Modos de Ser e de Aprender. Educação \& Realidade, Porto Alegre, v. 40, n. 4, p. 1079-1102, out./dez. 2015. Disponível em: https://www.scielo.br/pdf/edreal/v40n4/2175-6236-edreal-42057.pdf. Acesso em: 14 jan. 2021.

FOCHI, Paulo Sérgio. Abordagem da Documentação Pedagógica na Formação em Contextos de Educação Infantil. RELAdEI (Revista Latinoamericana de Educación Infantil), v. 7, n. 2-3, p. 149-158, dez. 2018. Disponível em: https:// revistas.usc.gal/index.php/reladei/article/view/5030/6231. Acesso em: 08 maio 2021.

HAAS, Clarissa; BAPTISTA, Claudio Roberto. Currículo e Educação Especial: uma relação de (re) invenção necessária a partir das imagens-narrativas dos cotidianos escolares. In: Reunião Anual da Reunião Nacional da Associação Nacional de Pós-Graduação e Pesquisa em Educação (Anped), 37., 2015, Florianópolis. Anais [...] Florianópolis, SC: Universidade Federal de Santa Catarina (UFSC), 2015. Disponível em: https://anped.org.br/sites/default/files/trabalho-gt15-4199.pdf. Acesso em: 07 abr. 2020.

HAAS, Clarissa; MORO, Tatiele Bolson. O núcleo de acessibilidade como mediador da educação inclusiva em uma instituição pública de educação profissional e tecnológica. Revista Transmutare, Curitiba, v. 5, p. 01-19, 2020. Disponível em: https://periodicos.utfpr.edu.br/rtr/article/view/12908/8206. Acesso em: 23 abr. 2020.

HAAS, Clarissa; SOZO, Carolina Mross. Políticas e práticas pedagógicas de educação inclusiva no Instituto Federal do Rio Grande do Sul (IFRS): em foco o papel do núcleo de acessibilidade. Revista Educação Especial em Debate, Espírito Santo, v. 5, n. 10, p. 52-72, jul./dez. 2020. Disponível em: https://periodicos.ufes.br/reed/article/view/32150. Acesso em: 16 abr. 2021.

HAAS, Clarissa; SOZO, Carolina Mross; RODRIGUES, Eduarda Andréia Pedron. O Plano Educacional Individualizado como documentação pedagógica para articulação entre currículo e educação inclusiva. In: Seminário Nacional de Educação Especial, 6. Seminário Capixaba de Educação Inclusiva, 17, 2020. Anais [...] Espírito Santo, ES, out. 2020. Disponível em: https://periodicos.ufes.br/snee/article/view/34345. Acesso em: 27 fev. 2021.

IANES, Dario. L'evoluzione dell'insegnante di sostegno. Verso uma didattica inclusiva. Trento: Erickson, 2014. p. 159.

IFRS. Instituto Federal de Educação, Ciência e Tecnologia do Rio Grande do Sul. Resolução no 020, de 25 de fevereiro de 2014 - Regulamento dos Núcleos de Atendimento às Pessoas com Necessidades Educacionais Específicas (NAPNEs) do IFRS. Bento Gonçalves, RS: IFRS, 2014. Disponível em: https://ifrs.edu.br/wp-content/uploads/2017/09/Resolucao-20-14.pdf. Acesso em: 16 mar. 2020.

IFRS. Instituto Federal de Educação, Ciência e Tecnologia do Rio Grande do Sul. Instrução Normativa no 12, de 21 de dezembro de 2018. Regulamenta os fluxos e procedimentos de identificação, acompanhamento e realização do Plano Educacional Individualizado (PEI) dos estudantes com necessidades educacionais específicas do IFRS. Bento Gonçalves, RS: IFRS, 2018. Disponível em: https://ifrs.edu.br/wp-content/uploads/2018/12/IN-PEI-21.12_Publicada_em_271218. pdf. Acesso em: 16 mar. 2020.

IFRS. Instituto Federal de Educação, Ciência e Tecnologia do Rio Grande do Sul. Sobre o IFRS. Bento Gonçalves, RS: IFRS, 2019. Disponível em: https://ifrs.edu.br/institucional/sobre/. Acesso em: 20 mar. 2020.

IFRS. Instituto Federal de Educação, Ciência e Tecnologia do Rio Grande do Sul. Instrução Normativa PROEN nº 07, de 04 de setembro de 2020. Regulamenta os fluxos e procedimentos de identificação, acompanhamento e realização do Plano Educacional Individualizado (PEI) dos estudantes com necessidades educacionais específicas do IFRS. Bento Gonçalves, RS: IFRS, 2020. Disponível em: https://ifrs.edu.br/wp-content/uploads/2020/09/IN-07-2020-Plano-Educacional-Individualizado-PEI.pdf. Acesso em: 06 set. 2020.

KORCZAK, Janusz. Como amar uma criança. 4. ed. São Paulo: Paz e Terra. 1997. 
LÜDKE, Menga; ANDRÉ, Marli Eliza Dalmazo Afonso de. Pesquisa em educação: abordagens qualitativas. Rio de Janeiro: E. P. U., 2017.

MALAGUZZI, Loris. História, ideias e filosofia básica. In: EDWARDS, Carolyn; GANDINI, Leila; FORMAN, George. As cem linguagens da criança: a abordagem da Reggio Emília na educação da primeira infância. vol. 1. Porto Alegre: Penso, 2016.

MARCONI, Marina de Andrade; LAKATOS, Eva Maria. Fundamentos de metodologia científica. 8. ed. [3. reimpr.]. São Paulo: Altas, 2019. Disponível em: https://integrada.minhabiblioteca.com.br/\#/books/9788597010770/. Acesso em: 13 set. 2020.

MARQUES, Amanda Cristina Teagno Lopes; ALMEIDA, Maria Isabel de. A documentação pedagógica na abordagem italiana: apontamentos a partir de pesquisa bibliográfica. Revista Diálogo Educacional, Curitiba, v. 12, n. 36, p. 441458, maio/ago. 2012. Disponível em: https://periodicos.pucpr.br/index.php/dialogoeducacional/article/view/4639/4582. Acesso em: 25 jun. 2020.

MARQUES, Amanda Cristina Teagno Lopes; ALMEIDA, Maria Isabel de. A documentação pedagógica no pensamento de Célestin Freinet. Perspectiva, Florianópolis, v. 35, n. 1, p. 214-236, jan./mar. 2017. Disponível em: https://periodicos. ufsc.br/index.php/perspectiva/article/download/2175-795X.2017v35n1p214/pdf/174845. Acesso em: 09 maio 2021.

MESQUITA, Amélia Maria Araújo. Currículo e Educação Inclusiva: as políticas curriculares nacionais. Espaço do currículo, v. 03, n. 1, p. 305-315, 2010. Disponível em: http://periodicos.ufpb.br/ojs2/index.php/rec/article/view/9093/4781. Acesso em: 11 abr. 2020.

OLIVEIRA, Lígia Maria Nogueira; CAIADO, Kátia Regina Moreno. Competência técnica e compromisso político do professor de sala de recursos: implicação na escolarização dos alunos com baixa visão. In: TEZZARI, Mauren et al. (org.). Docência e inclusão escolar: percursos de formação e de pesquisa. Marília: Associação Brasileira de Pesquisadores em Educação Especial (ABPEE), 2020. p. 163-180. Disponível em: https://www.ufrgs.br/colegiodeaplicacao/wp-content/ uploads/2020/09/docencia-e-inclusao-escolar-4.pdf. Acesso em: 28 nov. 2020.

OLIVEIRA, Lisiane Cézar de; SIMON, Maria Inês; BRENNER, Fabrício Kaemmerer. ACALM - Assistente de Comunicação Alternativa e Aumentativa Móvel. In: SONZA, Andréa Poletto; SALTON, Bruna Poletto; STRAPAZZON, Jair Adriano (org.). Soluções Acessíveis: experiências inclusivas no IFRS. Porto Alegre: Companhia Rio-Grandense de Artes Gráficas (CORAG), 2014. p. 194-202. Disponível em: https://drive.google.com/file/d/17CuUwrkrEQHJ8PKicd62oR98at0vokLG/view. Acesso em: 26 maio 2020.

PINAZZA, Mônica Appezzato; FOCHI, Paulo Sérgio. Documentação Pedagógica: observar, registrar e (re)criar significados. Revista Linhas. Florianópolis, v. 19, n. 40, p. 184-199, maio/ago. 2018. Disponível em: http://www.revistas. udesc.br/index.php/linhas/article/view/1984723819402018184/pdf. Acesso em: 22 jun. 2020.

SILVA, Luan Rosa da et al. Acessibilidade e Inclusão escolar no IFRS - Campus Caxias do Sul. In: Jornada de Ensino, Pesquisa e Extensão do IFRS - Campus Caxias do Sul, 4., 2019. Anais [...] Caxias do Sul, RS, v. 2, p. 41, dez. 2019. Disponível em: https://eventos.ifrs.edu.br/index.php/jornadacxdosul/jornadacxdosul2/paper/viewFile/8672/3863. Acesso em: 30 jun. 2020.

SONZA, Andréa Poletto; VILARONGA, Carla Ariela Rios; MENDES, Enicéia Gonçalves. Os NAPNEs e o Plano Educacional Individualizado nos Institutos Federais de Educação. Revista Educação Especial, Santa Maria, v. 33, p. 01-24, 2020. Disponível em: https://periodicos.ufsm.br/educacaoespecial/article/view/52842/html. Acesso em: 09 maio 2021.

TEZZARI, Mauren Lúcia. De atas à documentação pedagógica: a potência formadora/ transformadora dessa prática pedagógica no grupo de práticas. In: TEZZARI, Mauren et al. (org.). Docência e inclusão escolar: percursos de formação e de pesquisa. Marília: Associação Brasileira de Pesquisadores em Educação Especial (ABPEE), 2020. p. 31-42. Disponível em: https://www.ufrgs.br/colegiodeaplicacao/wp-content/uploads/2020/09/docencia-e-inclusao-escolar-4. pdf. Acesso em: 28 nov. 2020.

XAVIER, Maíra da Silva. Acessibilidade Curricular: refletindo sobre os conceitos e o trabalho pedagógico. 2018. 93p. Dissertação (Mestrado em Educação) - Universidade Federal de Santa Maria, Centro de Educação, Programa de Pós-Graduação em Educação, RS, 2018. Disponível em: https://repositorio.ufsm.br/bitstream/handle/1/17084/DIS_PPGEDUCACAO_2018_XAVIER_MAIRA.pdf?sequence=1\&isAllowed=y. Acesso em: 03 dez. 2020.

Data de submissão: $14 / 05 / 2021$

Data de aceite: 25/06/2021 